\title{
Analytical expression of concentrations of adsorbed CO molecules, $O$ atoms and oxide oxygen
}

\author{
Chinnasamy Thangapandi, Lakshmanan Rajendran* \\ Department of Mathematics, The Madura College, Madurai, India; ${ }^{*}$ Corresponding Author: raj sms@,rediffmail.com
}

Received 12 October 2012; revised 15 November 2012; accepted 27 November 2012

\begin{abstract}
A mathematical model of the oscillatory regimes of $\mathrm{CO}$ oxidation over plantinum-group metal catalysts are discussed. The model is based on nonstationary diffusion equation containing a nonlinear term related to Michaelis-Menten kinetics of the enzymatic reaction. This paper presents the analytical and numerical solution of the system of non-linear differential equations. Here the Homotopy perturbation method (HPM) is used to find out the analytical expressions of the concentration of $\mathrm{CO}$ molecules, $\mathrm{O}$ atom and oxide oxygen respectively. A comparison of the analytical approximation and numerical simulation is also presented. A good agreement between theoretical and numerical results is observed.
\end{abstract}

Keywords: Oscillatory Dynamics; Reaction-Diffusion; Boundary Value Problems; Homotopy Perturbation Method

\section{INTRODUCTION}

Rate auto-oscillations in a heterogeneous catalytic reaction were first discussed more than two decades ago [1-3]. Some heterogeneous systems which show oscillatory behaviour on catalysts with various structures in a wide pressure range are presently known. One of the most extensively studied heterogeneous catalytic reactions exhibiting oscillatory dynamics is $\mathrm{CO}$ oxidation on platinum catalysts.

Various mathematical models are used in detailed analysis of the mechanism of the rate oscillations in catalytic CO oxidation. These models are based on a set of nonlinear ordinary differential equations [4-12]. Microscopic stochastic models by using the Monte Carlo method [13-18] one of the most interesting in theoretical investigation of the dynamics of fluctuating reaction systems. These stochastic models are based on detailed information concerning the elementary steps of the reaction, the structure of the catalyst surface, and the mobil- ity of species in the adsorption layer.

Therefore, the theoretical investigation and explanation of complex dynamic phenomena on a catalyst surface cannot be comprehensive. It is necessary to develop systems of consistent mathematical models describing the evolution of reaction systems on different spatial scales. This would allow the advantages of different classes of mathematical models.

Recently Kurkina and Semendyaeva [3] described the oscillatory dynamical system which includes a Monte Carlo simulation and adsorption layer approximation. To our knowledge no analytical expressions of the concentration of $\mathrm{CO}$ molecules, $\mathrm{O}$ atom and oxide oxygen have been derived from the system. The purpose of the communication is to derive the analytical expression of $\theta_{\mathrm{CO}}(t), \theta_{\mathrm{O}}(t)$, and $\theta_{\mathrm{O} *}(t)$ by solving the system of non-linear differential equation using Homotopy perturbation method.

\section{MATHEMATICAL FORMULATION OF BOUNDARY VALUE PROBLEM}

The oscillatory dynamics of the thickness shear model (TSM) kinetic network will be described using Lattice gas model. In this model any lattice site may be free $(*)$ or occupied by an adsorbed carbon monoxide molecule $\mathrm{CO}_{\text {ads }}$, an adsorbed oxygen atom $\mathrm{O}_{\text {ads }}$ or an adsorbed oxide oxygen atom $\mathrm{O}_{\text {ads }}^{*}$. The thickness shear mode (TSM) kinetic network includes the Langmuir-Hinshelwood mechanism [3].

$$
\begin{gathered}
\mathrm{CO}_{\text {gas }}+(*) \leftrightarrow \mathrm{CO}_{\text {ads }}, \\
\mathrm{O}_{2, \text { gas }}+2(*) \rightarrow 2 \mathrm{O}_{\text {ads }}, \\
\mathrm{CO}_{\text {ads }}+\mathrm{O}_{\mathrm{ads}} \rightarrow \mathrm{CO}_{2} \uparrow+2(*)
\end{gathered}
$$

and the formation and removal of surface oxide,

$$
\begin{aligned}
& \mathrm{O}_{\mathrm{ads}} \rightarrow \mathrm{O}_{\mathrm{ads}}^{*}, \\
& \mathrm{O}_{\mathrm{ads}}^{*}+\mathrm{CO}_{\mathrm{ads}} \rightarrow \mathrm{CO}_{2} \uparrow+2(*)
\end{aligned}
$$

Furthermore, we consider the migration of adsorbed species via a vacant-site mechanism: 


$$
\begin{gathered}
\mathrm{CO}_{\mathrm{gas}}+(*) \leftrightarrow(*)+\mathrm{CO}_{\mathrm{ads}}, \\
\mathrm{O}_{\mathrm{ads}}+(*) \leftrightarrow(*)+\mathrm{O}_{\mathrm{ads}}^{*}, \\
\mathrm{O}_{\mathrm{ads}}^{*}+(*) \leftrightarrow(*)+\mathrm{O}_{\mathrm{ads}}^{*} .
\end{gathered}
$$

Here, $(\mathrm{CO})_{\mathrm{gas}}$ and $\left(\mathrm{O}_{2}\right)_{\text {gas }}$ are molecules in the gas phase. Two-site process occurs on adjacent lattice sites. The rate of a two-site process is defined for a pair of sites, and the rate of a one-site process is defined for one site. The surface oxide formation step (4) is viewed as a one-site process, and step (5) is a two-site process. It is assumed that oxide oxygen retains its reactivity (see step (5)) and markedly decreases the activity of the catalyst in reactant adsorption from the gas phase.

\section{STOCHASTIC AND DETERMINISTIC MODELS}

The basic kinetic equations in a multidimensional system will be solved by approximate methods. In Monte Carlo stochastic modelling, state trajectories are constructed for the reaction system in the state space. Stochastic models describe the evolution of a selected lattice fragment at the atomic level. According to the above kinetic network, the variation of $\mathrm{CO}_{\text {ads }}, \mathrm{O}_{\text {ads }}$ and $\mathrm{O}_{\text {ads }}^{*}$ concentrations are described by a set of following nonlinear differential equations [4]:

$$
\begin{gathered}
\frac{\mathrm{d} \theta_{\mathrm{CO}}}{\mathrm{d} t}=k_{1}\left(1-\theta_{\mathrm{CO}}-\theta_{\mathrm{O}}-\theta_{\mathrm{O} *}\right)-k_{-1} \theta_{\mathrm{CO}} \\
-4 k_{3} \theta_{\mathrm{CO}} \theta_{\mathrm{O}}-4 k_{5} \theta_{\mathrm{CO}} \theta_{\mathrm{O}^{*}} \\
\frac{\mathrm{d} \theta_{\mathrm{O}}}{\mathrm{d} t}=4 k_{2}\left(1-\theta_{\mathrm{CO}}-\theta_{\mathrm{O}}-\theta_{\mathrm{O} *}\right)^{2}-4 k_{3} \theta_{\mathrm{CO}} \theta_{\mathrm{O}}-k_{4} \theta_{\mathrm{O}} \\
\frac{\mathrm{d} \theta_{\mathrm{O}^{*}}}{\mathrm{~d} t}=k_{4} \theta_{\mathrm{O}}-4 k_{5} \theta_{\mathrm{CO}} \theta_{\mathrm{O}^{*}}
\end{gathered}
$$

The initial conditions are as follows:

$$
\begin{aligned}
& \theta_{\mathrm{CO}}(t=0)=\theta_{\mathrm{CO}}^{o}, \theta_{\mathrm{O}}(t=0)=\theta_{\mathrm{O}}^{o}, \\
& \theta_{\mathrm{O}^{*}}(t=0)=\theta_{\mathrm{O}^{*}}^{o}
\end{aligned}
$$

Here, $\theta_{\mathrm{CO}}(t), \theta_{\mathrm{O}}(t)$, and $\theta_{\mathrm{O} *}(t)$ are the concentrations of adsorbed $\mathrm{CO}$ molecules and $\mathrm{O}$ atoms and oxide oxygen, respectively, and $k_{1}, k_{-1}, k_{2}, \cdots, k_{8}$ are the rate constants of elementary steps. The normalization conditions are as follows:

$$
\begin{aligned}
& 0 \leq \theta_{\mathrm{CO}} \leq 1,0 \leq \theta_{\mathrm{O}} \leq 1,0 \leq \theta_{\mathrm{O}^{*}} \leq 1, \\
& \text { and } 0 \leq \theta_{\mathrm{CO}}+\theta_{\mathrm{O}}+\theta_{\mathrm{O}^{*}} \leq 1
\end{aligned}
$$

To simplify, we can assume that $u=\theta_{\mathrm{CO}}, v=\theta_{\mathrm{O}}$ and $w=\theta_{\mathrm{O}^{*}}$ The above Eqs.9-11 become

$$
\begin{gathered}
\frac{\mathrm{d} u}{\mathrm{~d} t}=k_{1}(1-u-v-w)-k_{-1} u-4 k_{3} u v-4 k_{5} u w \\
\frac{\mathrm{d} v}{\mathrm{~d} t}=4 k_{2}(1-u-v-w)^{2}-4 k_{3} u v-k_{4} v \\
\frac{\mathrm{d} w}{\mathrm{~d} t}=k_{4} v-4 k_{5} u w
\end{gathered}
$$

Now the boundary condition (12) (or initial conditions) becomes

$$
u(t=0)=u^{0}, v(t=0)=v^{0}, \text { and } w(t=0)=w^{0}
$$

where

$$
u^{0}=\theta_{\mathrm{CO}}^{*}, v^{0}=\theta_{\mathrm{O}}^{*}, w^{0}=\theta_{\mathrm{O}^{*}}^{0}
$$

\section{ANALYTICAL EXPRESSIONS OF CONCENTRATIONS USING HOMOTOPY PERTURBATION METHOD [HPM]}

Recently, many authors have applied the HPM to various problems by demonstrating the efficiency of the HPM in handling non-linear structures and solving various physics and engineering problems [16-19]. This method is a combination in topology and classic perturbation techniques. Ji Huan He used the HPM to solve the light hill equation [20], the Duffing equation [21] and the Blasius equation [22]. The idea has been used to solve non-linear boundary value problems, integral equations and many other problems [23-27]. The HPM is unique in its applicability, accuracy and efficiency. The HPM uses the imbedding parameter $p$ as a small parameter and only a few iterations are needed to search for an asymptotic solution. Using this method (see Appendix A), we can obtain the following solution to Eqs.14-16 for the given boundary conditions (Eq.17).

$$
\begin{aligned}
u(t)=\theta_{\text {CO }}(t)=A+\left(u^{0}-A\right) \mathrm{e}^{-l t}+\frac{A\left(1-\mathrm{e}^{l t}\right)}{\mathrm{e}^{l t}}\left(B+w^{0}+\frac{4 k_{3} B}{l}+\frac{4 k_{5}}{l} w^{0}-4\left(u_{0}^{0}-A\right)\left(k_{5} B+k_{5} w\right) t\right. & \\
& \left.+\frac{\left(v^{0}-B\right)\left(4 k_{3}+k_{1}\right)\left(\mathrm{e}^{-(m-l) t}-1\right)}{m-l}+\frac{4 k_{3}\left(u^{0}-A\right)\left(v^{0}-B\right)\left(\mathrm{e}^{-m t}-1\right)}{m}\right)
\end{aligned}
$$




$$
\begin{aligned}
v(t)= & \theta_{0}(t)=B+t\left(v^{0}-B\right) \mathrm{e}^{-m t} \\
& +\mathrm{e}^{-m t}\left[8 k_{2}\left[\left(A+B+w^{0}\right)\left(v^{0}-B\right)\right]-4 k_{3} A\left(v^{0}-B\right) t+\frac{\left(\mathrm{e}^{-l t}-1\right)\left(u^{0}-A\right)\left(v^{0}-B\right)\left(4 k_{3}-8 k_{2}\right)}{l}\right. \\
& +\frac{\left(\mathrm{e}^{-(l-m) t}-1\right)\left[\left(4 k_{3} B-8 k_{2} A\right)\left(u^{0}-A\right)+8 k_{2}\left(1-B-w^{0}\right)\right]}{l-m} \\
& \left.\left.+\left(\mathrm{e}^{m t}-1\right) \frac{\left[4 k_{2}\left[A^{2}+B^{2+}+\left(w^{0}\right)^{2}+2 A w^{0}-2 w^{0}(1-B)-2 A(1-B)-4 k_{3} A B\right]\right]}{m}\right]\right] \\
& \left.+4 k_{2}\left[\frac{\left.\left(1-\mathrm{e}^{-(2 l-m) t}\right)\right]}{2 l-m}\left(u^{0}-A\right)^{2}+\frac{\left(1-\mathrm{e}^{-m t}\right)}{m}\left(v^{0}-B\right)^{2}\right]\right]
\end{aligned}
$$

$$
\begin{aligned}
& w(t)=\theta_{\left(\theta^{*}\right)}(t) \\
& =w^{0}+\left(k_{4} B-4 k_{3} A w^{0}\right) t \\
& \quad+\frac{k_{4}}{m}\left(v^{0}-B\right)\left(1-\mathrm{e}^{-m t}\right)+\frac{4 k_{5}\left(u^{0}-A\right) w^{0}\left(\mathrm{e}^{-l t}-1\right)}{l}
\end{aligned}
$$

where

$$
A=k_{1} / l, B=4 k_{2} / m, m=k_{4}+8 k_{2}, l=k_{1}+k_{-1}
$$

The Eqs.18-20 represent the new closed form of analytical expression of concentrations of $\mathrm{CO}$ molecules, $\mathrm{O}$ atom and oxide oxygen for all values of rate constant and time.

\section{ANALYTICAL EXPRESSION OF CONCENTRATION FOR STEADY STATE CONDITION}

For the case of steady state, the Eqs.14-16 become

$$
\begin{gathered}
k_{1}(1-u-v-w)-k_{-1} u-4 k_{3} u v-4 k_{5} u w=0 \\
4 k_{2}(1-u-v-w)^{2}-4 k_{3} u v-k_{4} v=0 \\
k_{4} v-4 k_{5} u w=0
\end{gathered}
$$

Solving the above non-linear algebraic equation by using Maple software, we can obtain the concentration of $\mathrm{CO}$ molecule, $\mathrm{O}$ atom and oxide oxygen as follows:

$$
u=\theta_{\mathrm{CO}}=0, v=\theta_{\mathrm{O}}=0, w=\theta_{\mathrm{O}^{*}}=1 .
$$

\section{NUMERICAL SOLUTION}

In order to test accuracy of this method the non-linear differential Eqs.14-16 for the boundary conditions (Eq.17) are solved by numerical methods. The function pdex4 in Matlab software was used to solve these equations. It is a function of solving the initial boundary value problems for non-linear differential equations. The Matlab program is also given in Appendix B. The numerical results are also compared with our analytical results in Figures 1(a)-(d). A satisfactory agreement is noted here.

\section{DISCUSSION}

Figures 1(a)-(d) represent the non steady state concentration of CO molecules $u(t)$ or $\theta_{\mathrm{CO}}(t)$, O atom $v(t)$ or $\theta_{\mathrm{O}}(t)$ and oxide oxygen $w(t)$ or $\theta_{\mathrm{O}^{*}}(t)$ for all values of rate constant and time. From the figure it is evident that the value of the concentration of $\mathrm{CO}$ molecule decrease from its initial value of concentration and reaches the steady state value zero when $t=2 \mathrm{sec}$ for all values of rate constant. From the figures it is also inferred that the value of concentration of $\mathrm{O}$ atom rises initially and reaches the maximum value when $t \approx 0.5 \mathrm{sec}$ and then decreases gradually. The concentration of $\mathrm{O}$ atom attains the steady state value when $t=10 \mathrm{sec}$. From this figure it is also observed that the concentration of oxide oxygen always increases when time increases and reaches the steady state value 1 when $t=5 \mathrm{sec}$ for all values of rate constant. From this figure it is to conclude that $0 \leq \theta_{\mathrm{CO}}+\theta_{\mathrm{O}}+\theta_{\mathrm{O}^{*}} \leq 1$ for all values of time and rate constant.

\section{CONCLUSION}

The theory of the dynamics of catalysts $\mathrm{CO}$ oxidation in the frame work of the Thickness shear mode kinetic is described. Approximate analytical solutions to the system of non-linear reaction equations are presented using Homotopy perturbation method. A simple, straight forward and a new method of estimating the concentrations of $\mathrm{CO}$ molecules, $\mathrm{O}$ atom and Oxide oxygen are derived. This analytical result will be useful to know the behaviour of the reaction system. A good agreement with the numerical simulation data is also noted. The extension of 


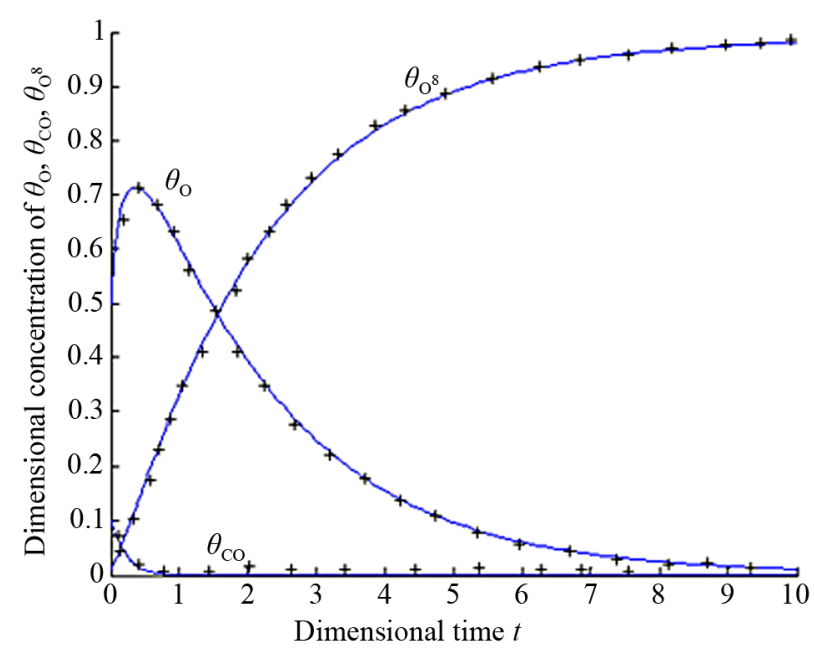

(a)

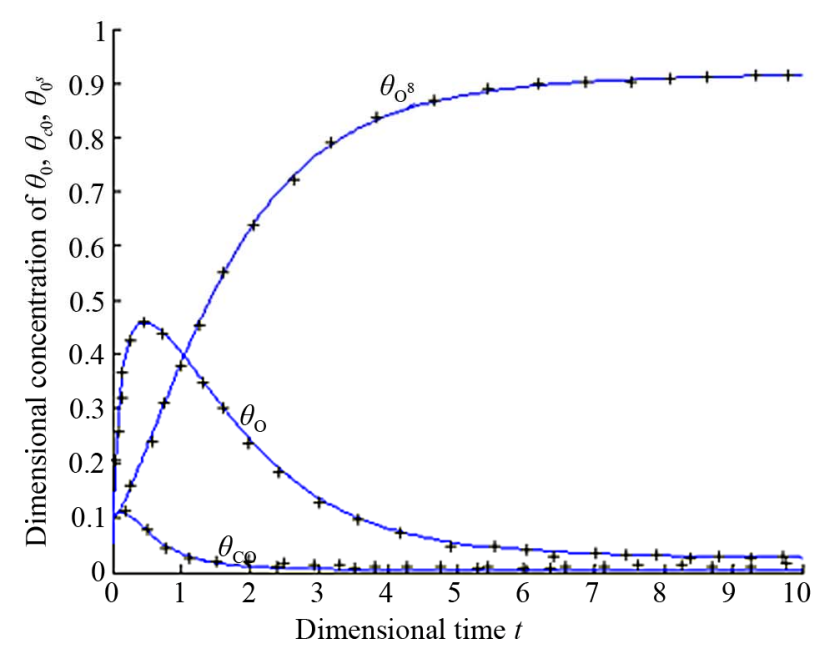

(c)

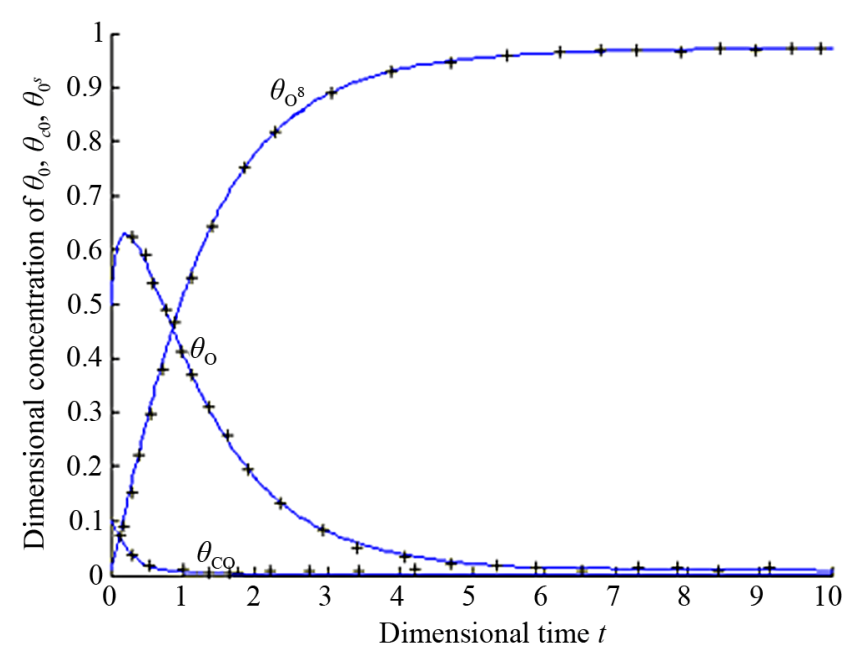

(b)

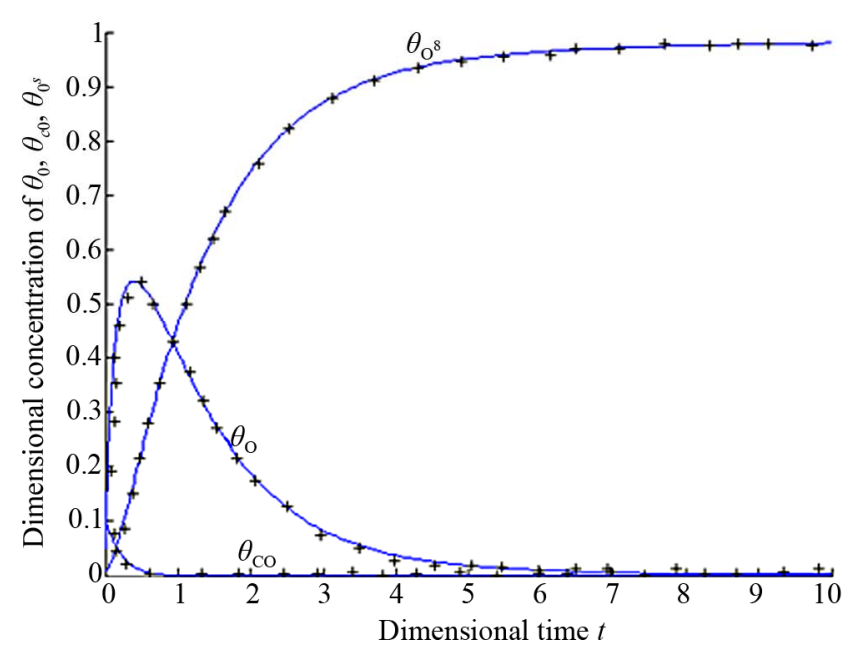

(d)

Figure 1. Dimensional concentration profile of adsorbed $\mathrm{CO}$ molecules $\theta_{\mathrm{CO}}, \mathrm{O}$ atom $\theta_{\mathrm{O}}$ and oxide oxygen $\theta_{\mathrm{O}}^{*}$ for various values of parameters and initial concentration. (a) $k_{1}=0.1, k_{-1}=2, k_{2}=5, k_{4}=0.5, k_{5}=2, k_{3}=1, \theta_{\mathrm{O}}^{o}=0.1, \theta_{\mathrm{O}^{8}}^{o}=0.01, \theta_{\mathrm{CO}}^{0}=0.5 ;$ (b) $k_{1}=0.5$, $k_{-1}=2, k_{2}=5, k_{4}=1, k_{5}=2, k_{3}=1, \theta_{\mathrm{O}}^{o}=0.1, \theta_{\mathrm{O}^{8}}^{o}=0.5, \theta_{\mathrm{CO}}^{0}=0.01$; (c) $k_{1}=0.5, k_{-1}=1, k_{2}=2, k_{4}=1, k_{5}=2, k_{3}=0.1$, $\theta_{\mathrm{O}}^{o}=0.1, \theta_{\mathrm{O}^{8}}^{o}=0.5, \theta_{\mathrm{CO}}^{0}=0.01 ;$ (d) $k_{1}=0.1, k_{-1}=4, k_{2}=2, k_{4}=1, k_{5}=2, k_{3}=0.1, \theta_{\mathrm{O}}^{o}=0.1, \theta_{\mathrm{O}^{8}}^{o}=0.05, \theta_{\mathrm{CO}}^{0}=0.1$.

this method with more modelling and simulation procedure to the some of the non-linear reaction diffusion mechanism in biosensor [28] seems possible.

\section{ACKNOWLEDGEMENTS}

This work is supported by the University Grants Commission (UGC) (Ref. No. F. No. 39 - 58/2010(SR)) and Council of Scientific and Industrial Research (CSIR) (No.01 (2442)/10/EMR-II), Government of India. The authors are thankful to the Secretary, the Principal, The Madura College, Madurai, India for their constant encouragement.

\section{REFERENCES}

[1] Hugo, P. and Jakubith, M. (1972) Dynamic behavior and kinetics of carbon monoxide-oxidation at the platinum catalyst. Chemie Ingenieur Technik, 44, 383-387. doi:10.1002/cite. 330440608

[2] Beusch, H., Fieguth, P. and Wicke, E. (1972) Kinetically and thermally induced instabilities in reaction behavior of individual catalyst particles. Chemie Ingenieur Technik, 44, 445-451. doi:10.1002/cite.330440702

[3] Kurkina, E.S. and Semendyaeva, N.L. (2005) Oscillatory dynamics of co oxidation on platinum-group metal catalysts. Kinetics and Catalysis, 46, 453-463. doi:10.1007/s10975-005-0098-4

[4] Sales, B.C., Turner, J.E. and Maple, M.B. (1982) Oscillatory oxidation of CO over Pt, Pd and Ir catalysts: Theory. Surface Science, 114, 381-394. doi:10.1016/0039-6028(82)90692-6

[5] Eigenberger, G. (1978) Steady state multiplicity of the 
kinetic model of CO oxidation reaction. Chemical Engineering Science, 33, 1255-1263.

doi:10.1016/0009-2509(78)85091-X

[6] Bykov, V.I., Yablonskii, G.S. and Elokhin, V.I. (1981) Steady state multiplicity of the kinetic model of CO oxidation reaction. Surface Science Letters, 107, 334-338.

[7] Yablonskii, G.S., Bykov, V.I. and Elokhin, V.I. (1984) Kinetics of model reactions of heterogeneous catalysis. Nauka, Novosibirsk. (in Russian)

[8] Slin'ko, M.M. and Slin'ko, M.G. (1982) Rate oscillations in heterogeneous catalyzed reactions. Kinetics and $\mathrm{Ca}$ talysis, 23, 1421.

[9] Makeev, A.G. and Semendyaeva, N.L. (1996) A note on g-derivative and g-integral. Tatra Mountains Mathematical Publications, 8, 76.

[10] Slinko, M.M., Kurkina, E.S., Liauw, M.A. and Jaeger, N.J. (1999) Mathematical modeling of complex oscillatory phenomena during CO oxidation over Pd zeolite catalysts. Journal of Chemical Physics, 111, 8105-8114. doi:10.1063/1.480144

[11] Peskov, N.V., Slinko, M.M. and Jaeger, N.I. (2002) Stochastic model of reaction rate oscillations in the $\mathrm{CO}$ oxidation on nm-sized palladium particles. Journal of Chemical Physics, 116, 2098-2106. doi:10.1063/1.1429234

[12] Zhdanov, V.P. (2002) Monte carlo simulations of oscillations, chaos and pattern formation in heterogeneous catalytic reactions. Surface Science Reports, 45, 231-326. doi:10.1016/S0167-5729(01)00023-1

[13] Latkin, E.I., Elokhin, V.I. and Gorodetskii, V.V. (2001) Monte carlo model of oscillatory $\mathrm{CO}$ oxidation having regard to the change of catalytic properties due to the adsorbate-induced $\operatorname{Pt}(1 \quad 0 \quad 0)$ structural transformation. Journal of Molecular Catalysis A: Chemical, 166, 23-30. doi:10.1016/S1381-1169(00)00468-4

[14] Elokhin V.I. and Latkin E.I. (1995) Statistic lattice model of oscillating and wave phenomena over the catalyst surface during CO oxidation. Doklady Akademii Nauk, 344, 56-61. (in Russian)

[15] Elokhin, V.I., Latkin, E.I., Matveev, A.V. and Gorodetskii, V.V. (2003) Application of statistical lattice models to the analysis of oscillatory and auto wave processes on the reaction of carbon monoxide oxidation over platinum and palladium surfaces. Kinetics and Catalysis, 44, 672-700. doi:10.1023/A:1026106509151

[16] Haario, H. and Seidman, T.I. (1994) Reaction and diffusion at a gas/liquid interface, II. SIAM Journal on Mathematical Analysis, 25, 1069-1084. doi:10.1137/S0036141092234712

[17] He, J.H. (1999) Homotopy perturbation technique. Com- puter Methods in Applied Mechanics and Engineering, 178, 257-262. doi:10.1016/S0045-7825(99)00018-3

[18] He, J.-H. (2000) A coupling method of homotopy technique and a perturbation technique for non-linear problems. Computer Methods in Applied Mechanics and Engineering, 35, 37-43. doi:10.1016/S0020-7462(98)00085-7

[19] He, J.-H. (2003) Homotopy perturbation method: A new nonlinear analytical technique. Applied Mathematics and Computation, 135, 73-79. doi:10.1016/S0096-3003(01)00312-5

[20] He, J.-H. (2006) Homotopy perturbation method for solving boundary value problems. Physics Letters A, 350, 8788. doi:10.1016/i.physleta.2005.10.005

[21] He, J.-H. (2006) Some asymptotic methods for strongly nonlinear equations. International Journal of Modern Physics B, 20, 1141-1199. doi:10.1142/S0217979206033796

[22] Kalachev, L.V. and Seidman, T.I. (2003) Singular perturbation analysis of a stationary diffusion/reaction system exhibiting a corner-type behavior in the interval interior. Journal of Mathematical Analysis and Applications, 288, 722-743. doi:10.1016/j.jmaa.2003.09.024

[23] Li, S.J. and Liu, Y.X. (2006) An improved approach to nonlinear dynamical system identification using pid neural networks. International Journal of Nonlinear Sciences and Numerical Simulation, 7, 177-182.

[24] Loghambal, S. and Rajendran, L. (2010) Mathematical modeling of diffusion and kinetics of amperometric immobilized enzyme electrodes. Electrochim Acta, 55, 5230-5238. doi:10.1016/j.electacta.2010.04.050

[25] Meena, A. and Rajendran, L. (2010) Mathematical modeling of amperometric and potentiometric biosensors and system of non-linear equations-Homotopy perturbation approach. Journal of Electroanalytical Chemistry, 644, 50-59. doi:10.1016/j.jelechem.2010.03.027

[26] Anitha, S., Subbiah, A., Subramaniam S. and Rajendran, L. (2011) Analytical solution of amperometric enzymatic reactions based on Homotopy perturbation method. Electrochimica Acta, 56, 3345-3352. doi:10.1016/j.electacta.2011.01.014

[27] Ananthaswamy, V. and Rajendran, L. (2012) Analytical solution of two-point non linear boundary value problems in a porous catalyst particles. International Journal of Mathematical Archieve, 3, 810-821.

[28] Baronas, R., Ivanauskas, F. Kulys, J. (2010) Mathematical modelling of biosensors: An Introduction for chemists and mathematicians. Springer, Dordrecht, Heidelberg, London, New York. 


\section{APPENDIX A}

\section{Analytical Solution of the Nonlinear Equations Using Homotopy Perturbation Method}

In this appendix, we indicate how Eqs.14-16 may be solved using HPM. To find the solution of Eqs.14-16, we first construct a homotopy as follows [16-19]:

$$
\begin{gathered}
(1-p)\left[\frac{\mathrm{d} u}{\mathrm{~d} t}+\left(k_{1}+k_{-1}\right) u-k_{1}\right] \\
+p\left[\frac{\mathrm{d} u}{\mathrm{~d} t}-k_{1}(1-u-v-w)+u\left(k_{-1}+4 k_{3} v+4 k_{5} w\right)\right]=0 \\
(1-p)\left[\frac{\mathrm{d} v}{\mathrm{~d} t}+\left(k_{4}+8 k_{2}\right) v-4 k_{2}\right] \\
+p\left[\frac{\mathrm{d} v}{\mathrm{~d} t}-4 k_{2}(1-u-v-w)^{2}+4 k_{3} u v+k_{4} v\right]=0 \\
(1-p) \frac{\mathrm{d} w}{\mathrm{~d} t}+p\left[\frac{\mathrm{d} w}{\mathrm{~d} t}-k_{4} v+4 k_{5} u w\right]=0
\end{gathered}
$$

where $p \in[0,1]$ is an embedding parameter. According to HPM, we can first use the parameter $p$ as a "small parameter" and assume that the solution of Eqs.14-16 can be written as a power series in $p$.

$$
\begin{aligned}
& u=u_{0}+p u_{1}+p^{2} u_{2}+\cdots \\
& v=v_{0}+p v_{1}+p^{2} v_{2}+\cdots \\
& w=w_{0}+p w_{1}+p^{2} w_{2}+\cdots
\end{aligned}
$$

where $u_{0}, v_{0}$, and $w_{0}$ are zero-order solution (initial approximation) and $u_{1}, v_{1}, w_{1}$ are the first order approximate solution. When $p=0$, we get zero-order solution (initial approximate solution or solution of linear terms). Setting $p=1$, results in the approximate solution

of Eqs.14-16. Substituting Eqs.A4-A6 into Eqs.A1-A3 and comparing the coefficients of like powers of $p$ we obtain the following differential equations.

$$
\begin{gathered}
p^{0}: \frac{\mathrm{d} u_{0}}{\mathrm{~d} t}+\left(k_{1}+k_{-1}\right) u_{0}-k_{1}=0 \\
p^{1}: \frac{\mathrm{d} u_{1}}{\mathrm{~d} t}+\left(k_{1}+k_{-1}\right) u_{1}+k_{1}\left(v_{0}+w_{0}\right) \\
+4 k_{3} u_{0} v_{0}+4 k_{5} u_{0} w_{0}=0 \\
p^{0}: \frac{\mathrm{d} v_{0}}{\mathrm{~d} t}+\left(k_{4}+8 k_{2}\right) v_{0}-4 k_{2}=0 \\
p^{1}: \frac{\mathrm{d} v_{1}}{\mathrm{~d} t}+\left(k_{4}+8 k_{2}\right) v_{1} \\
-4 k_{2}\left(1-2 v_{0}+\left(1-u_{0}-v_{0}-w_{0}\right)^{2}\right)+4 k_{3} u_{0} v_{0}=0
\end{gathered}
$$

and

$$
\begin{gathered}
p^{0}: \frac{\mathrm{d} w_{0}}{\mathrm{~d} t}=0 \\
p^{1}: \frac{\mathrm{d} w_{1}}{\mathrm{~d} t}-k_{4} v_{0}+4 k_{5} u_{0} w_{0}=0
\end{gathered}
$$

The initial conditions in Equation (17) becomes

$$
\begin{gathered}
u_{0}(t=0)=u^{0}, v_{0}(t=0)=v^{0}, w_{0}(t=0)=w^{0} \\
u_{i}(t=0)=0, v_{i}(t=0)=0, w_{i}(t=0)=0, \text { for } i \geq 1
\end{gathered}
$$

Solving the equations using the initial conditions Equation (A14), we obtain the following results.

$$
\begin{gathered}
u_{0}(t)=A+\left(u^{0}-A\right) \mathrm{e}^{-l t} \\
v_{0}(t)=B+\left(v^{0}-B\right) \mathrm{e}^{-m t} \\
w_{0}(t)=w^{0}
\end{gathered}
$$

$$
\begin{aligned}
v_{1}(t)= & \mathrm{e}^{-m t}\left[\left(\mathrm{e}^{-(l-m) t}-1\right) \frac{\left[\left(4 k_{3} B-8 k_{2} A\right)\left(u^{0}-A\right)+8 k_{2}\left(1-B-w^{0}\right)\right]}{l-m}+\frac{\left(\mathrm{e}^{-l t}-1\right)\left(u^{0}-A\right)\left(v^{0}-B\right)\left(4 k_{3}-8 k_{2}\right)}{l}\right. \\
& +\left(\mathrm{e}^{m t}-1\right) \frac{\left[4 k_{2}\left[A^{2}+B^{2+}+\left(w^{0}\right)^{2}+2 A w^{0}-2 w^{0}(1-B)-2 A(1-B)-4 k_{3} A B\right]\right]}{m} \\
& \left.+4 k_{2}\left[\frac{\left[\left(1-\mathrm{e}^{-(2 l-m) t}\right)\right]}{2 l-m}\left(u^{0}-A\right)^{2}+\frac{\left(1-\mathrm{e}^{-m t}\right)}{m}\left(v^{0}-B\right)^{2}\right]+8 k_{2}\left[\left(A+B+w^{0}\right)\left(v^{0}-B\right)\right]-4 k_{3} A\left(v^{0}-B\right) t\right]
\end{aligned}
$$




$$
\begin{aligned}
w_{1}(t)= & \left(k_{4} B-4 k_{3} A w^{0}\right) t+\frac{k_{4}}{m}\left(v^{0}-B\right)\left(1-\mathrm{e}^{-m t}\right) \\
& +\frac{4 k_{5}\left(u^{0}-A\right) w^{0}\left(\mathrm{e}^{-l t}-1\right)}{l}
\end{aligned}
$$

According to the HPM, we can conclude that

$$
\begin{gathered}
u(t)=\lim _{p \rightarrow 1} u(t)=u_{0}+u_{1} \\
v(t)=\lim _{p \rightarrow 1} v(t)=v_{0}+v_{1} \\
w(t)=\lim _{p \rightarrow 1} w(t)=w_{0}+w_{1}
\end{gathered}
$$

where

$$
A=k_{1} / l, B=4 k_{2} / m, m=k_{4}+8 k_{2}, l=k_{1}+k_{-1} \quad \text { (A24) }
$$

After putting the Eqs.A15-A20 in the Eqs.A21-A24 we get the Eqs.18-20 in the text.

\section{APPENDIX B}

\section{Matlab Program to Find the Numerical Solution of Eqs.14-16}

function main 1

options = odeset ('RelTol',1e-6,'Stats','on');

$\%$ initial conditions

$\mathrm{T}=100$;

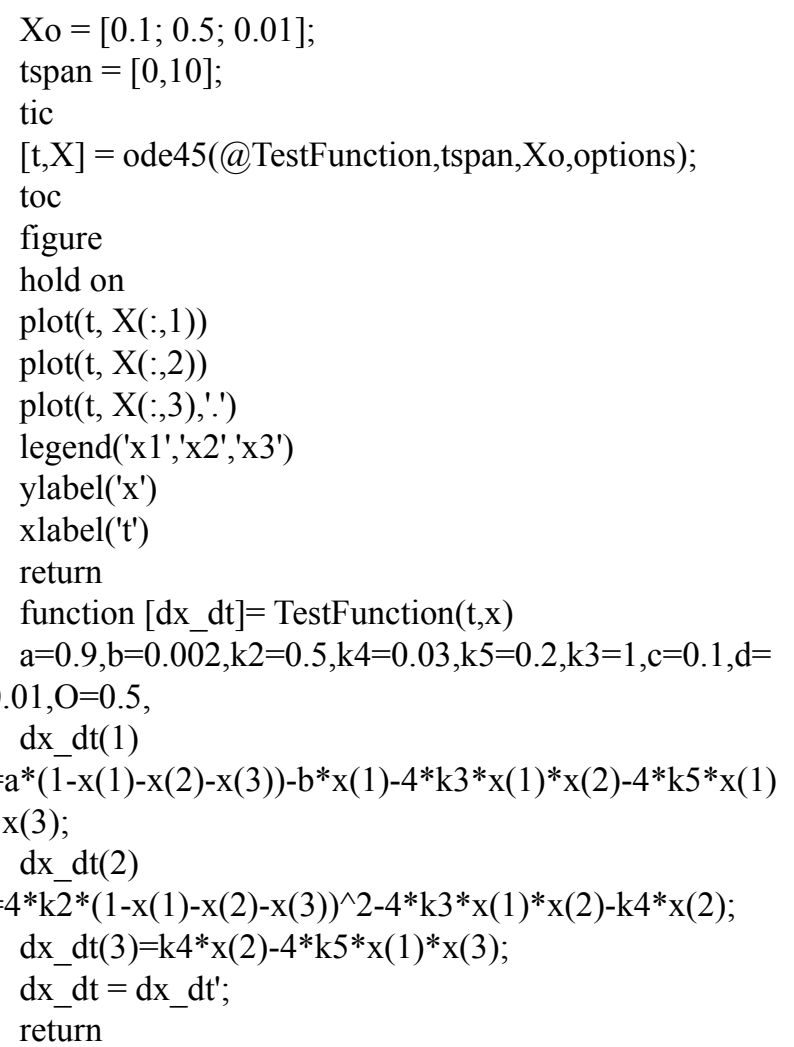

